\title{
Communication of Tourism Product; The case of Himara
}

\author{
Prof. Assoc. Dudi SULI ${ }^{1}$, Msc Ina ÇANI ${ }^{2}$, Hergys SULI ${ }^{3}$
}

\begin{abstract}
:
Tourism has and will be generally recognized as the world's largest industry. Its growth is creating rapid social, economic and environmental changes which expect detailed understanding and measures to be managed.

The market values of tourism can generally be realized by tourism products. This study aims to explore the potential and communication of tourism product; by studying the case of Himara, a city in south Albania - the study investigates how communication tourism product works in a real environment.

Nowadays, communication has become a major driver of tourism. Communication in tourism is another form of promoting tourism by involving not only linguistic means. Some people traveled specifically in order to gain a deeper understanding of the culture or heritage of a destination by what they have heard and read. In order to satisfy tourists' needs and expectations, tourism products typically attract consumers by the communication attributes. People hold a variety of misconceptions about communication of tourism product. The most common one is its confusion with marketing and promotion.

In general terms, tourism is commonly considered as a priority sector by Albanian Central and Local Government. Himara is a small city in southwest, holding high potential for tourism. It is widely considered an attractive destination of Albanian Riviera; and the overall objective of this study is to identify the issues and challenges in tourism promotion facing Himara.
\end{abstract}

Key words: tourism product, domestic tourism, life cycle, impacts, sustainable, inbound.

\section{Introduction}

How is tourism in Himara maintaining ties to its motherland and also creating a destination image in the international spectrum?

The last decades have seen a growing interest in tourism and related subject matters by the academic world. Having developed into the most

${ }^{1}$ Department of Agricultural Political Economy ${ }^{2}$ Dept: Foreign Languages

Agricultural University of Tirana, Albania.

${ }^{3}$ Plus Communication, Tirana, Albania 
predominant sector in world's economy, tourism could not have been ignored by the community of scholars. Explaining the phenomenon of tourism, its effects, its influence and relationships with other sectors of human activity, and attempts at predicting future developments and behaviors have increased in importance with significant numbers of people involved in such study.

Marketing communications forms a key aspect of the delivery of tourism and hospitality services. This sector is heavily dependent on marketing because of the industries special characteristics as services. However, marketing communications is a great deal more than simply about advertising. Getting the right messages to the right people is perhaps one of the most important factors in determining the success of this sector. Indeed marketing communications forms its own subfield of study within the discipline of marketing. ${ }^{1}$

The investigation presented in this study deals with the communication of a tourism product. Himara's enormous tourism potential has been realized by the central and local government of Albania and the Albanian Tourism Association. At the regional level however, authority is faced with many challenges. One of those is the performance of elaborated tourism development plans. This study focuses on these implementation issues. In order to allow a more in-depth research and formulation of recommendations, Himara is taken as an example for the sustainable development of the Albanian Riviera.

In order to well discuss the importance of developing tourism products, this study picks this Albanian southern region, the famous notable city of the Riviera, as the subject of the case study. It examines how the city provides welldeveloped cultural tourism products by using its rich cultural and natural resources. The growth of domestic tourism is favorable for the overall national tourism growth.

Analyses of the economic impact of tourism are generally based on tourist expenditure at a particular destination, giving rise to an increase in output in order to meet the higher demand. However, it would be wrong to limit the beneficial effects of tourism to directly observable expenditure by tourists on tourist supplies of goods and services, given the existence of indirect and induced effects that should also be estimated if a fully-comprehensive analysis is to be made. ${ }^{2}$

${ }^{1}$ Scott McCabe, Marketing Communications in Tourism and Hospitality, pg 2 ${ }^{2}$ A.D. Ramos, P.S. Jimenez, Tourism development: Economics, Management and Strategy, $p$ 203 


\section{Methodology}

The study is based on both primary and secondary data sources .

The secondary research consists of the literature review on extensions and its application to the reality of the tourism product. A supplementary theoretical basis for a better understanding of the attractions and resources will be produced, including the destination life cycle, customer satisfactions (needs/expectations/values) and communication (image). In addition, information collected from different sources including social conditions, statistic data etc. The information is assured from studies, journals, books, dissertations, websites, brochures etc.

The primary data findings on the extensions are based on a series of arranged interviews and with the helpful input from the inhabitants. However, the qualitative research has been utilized as the chief source for this study. This approach is used to get a deeper understanding of the concepts of "tourism product", "domestic tourism" and " tourism communication", and how the first two can contribute to the later. The general method aims to carry out qualitative research in order to analyze empirical concepts.

\section{Results}

The number of visitors who visit Albanian Riviera every year is growing very fast and the market tends increases year by year. For analyzing the characteristics of tourists in Himara, we use the result of the interviewed which was taken in a period of three weeks, March 2012. The tourists' age, occupation, travel purpose and travel mode were some of the prompt examined questions. The survey is considered faithful to the findings of research approaches. The examination of statistics is based on these subdivisions.

The primary role of the promotion thus is to convince the potential customers of the various advantages of buying or using the products and services of a particular enterprise, organization or a firm. ${ }^{3}$ It is impossible to develop tourism market without the main tool, people. As consequence, tourism/services cannot work without people/communication. Tourist has traveled to the destination to benefit from human services; not to get them from automatic serving machines. Television travel is no longer a single authoritative broadcasting voice which is heard but a multiplicity of 'ordinary' voices which allow viewers to work through a variety of more casual and varied messages. Deregulation and globalization have been matched by the development of unobtrusive lightweight equipment which can easily be transported and deployed and is not dependent on a studio. ${ }^{4}$

\footnotetext{
${ }^{3}$ G.P. Raju, Tourism Marketing and Management, pg 143

${ }^{4}$ P. M. Burns, M. Novelli, Tourism and Social Identities. p 185
} 
A SWOT analysis was performed with each of the interview participants and SMEs members from both a promotion and product development point of view. This includes Strengths, Weakness, Opportunities and Threat Analysis - SWOT Analysis, a review of the global and local trends which provide an outlook for Himara's tourism industry, an overview of its strategic position, and the whole of city priorities for tourism. Attached to the priorities is a hint of those areas within council who are responsible for the implementation of each priority. A SWOT analysis provides an opportunity to independently assess the competing development environment.

The significance of the SWOT Analysis lies in the fact that its findings taken seriously into account in the period of the drawing out of the strategy for the final forming of the agenda for the tourist promotion.

Strengths - are the qualities that enable the tourism destination to accomplish the overall mission and function.

- Lovely weather which is ideal for the tourists to come for summer holiday to escape the burning heat of the urban life.

- Vivid beauty of the Himara, which draws tourists away from the crowded and polluted towns and cities.

- Terrain is ideally suited for diverse adventure activities.

- Size and diversity of tourism products, attractions, accommodation and tourist experiences.

- Proximity to Corfu and Brindisi.

- Reputation as a chaste tourism destination.

- Attractiveness for hallmark events.

- Community support for tourism development.

- Iconic surf beaches and skyline.

- Typical Mediterranean Sea climate.

- Natural, Historical and Cultural Resources.

- National Primary Roads.

- Variety of Sports and Maritime Activities.

- Unexplored tourist places.

- Nearby the main European market.

Weaknesses, as divergent to the strengths, the weaknesses are disadvantages that are possible to act as a restriction for the tourist development. They are factors that reduce the output and good organization of either some or all the issues that are connected with the tourist growth and at the same time they are recorded as problems.

- Product's forms of Communication.

- Human resources management. 
- Seasonality.

- No experience on ecotourism, lack of management skills of local businesses in environmental management.

- Weak tourist information and distribution.

- Diverse transport access, including access from other countries and congestion within the city.

- Limited airline access due to the National Airport.

- Proximity to other countries of the Riviera.

Opportunities, concerns the current and future conditions of the tourist Market but also the "general environment "in which the prefecture of Himara is placed. These conditions have or are inclined to have positive influence in the development of the tourist arrivals and help the efforts to enrich the tourist product and to strengthen the tourist supply and competitiveness.

- European Union support.

- Increase in tourism demand size.

- Infrastructure development.

- Transportation.

- Advantages from the fact that Albania still is an unexploited country.

- Opportunities for employment and income generation for inhabitants.

- Exploitation of Visiting Friends and Relatives market.

- Exploitation of web- more current info.

- New and innovative tourism product and icons

- Nature-based tourism and coastal regions.

- Integrated transport system, including self-drive, public transport and private operators.

- Increased awareness of food and dining experiences.

- Develop cultural and lifestyle orientated tourism products in the city.

- Gold Coast Convention Centre and growth in business tourism in the city.

Threats, as opposed to the previous section it concerns the current or future Conditions of the general atmosphere they have a negative influence on the efforts to develop the tourist product of the prefecture.

- Environmental degradation.

- Infrastructure.

- Transfer of ecotourism from a friendly activity towards nature in a new product for the market.

- Uncoordinated approach to tourism development and planning.

- Urban collapse.

- Crime and safety problems.

- Community concerns about tourism. 
- Lack of innovative, world-class tourist product and infrastructure.

- Population growth.

- Remaining competitive to relation to other tourist destinations, both in Albania and abroad.

- Water supply and distribution.

- Lack of interest.

The Multidimensional SWOT Analysis is a perfectly structured way to use available information to analyze the negotiation counterpart. It allows each negotiator to view not only their own strategic position within the negotiation from various perspectives but also gives a good insight on the positioning of the rivaling parties ${ }^{5}$. Indeed Albanian Riviera is a potential destination with strong position in the domestic market. However, there are still internal and external factors which can have harmful effect on their performance and lead to strategic issues. From the results of case analysis, Himara has a leading position in Albanians holiday destination, but the tourism product should also consider other means of communication.

\section{Conclusions}

The study that conducted here is one of the few empirical studies that had as a purpose the examination of Albanian outbound travelers to the Himara. It was based on qualitative structured interviews that were taken from visitors; those that have been in destination for holidays, professional reasons, studies and group tourism. This study reveals the need to assess the cultural differences, values, and lifestyle of the Himara, Albania and formulate a pattern of the identity travel consumption in Europe. Hence, some unique travel samples in tourism were identified.

The study case arrayed a good example to provide outstanding tourism products. The strategies that Himara has adopted to display its products could be concluded as:

Emphasize the cultural topic. This southern city promotes itself as the one of the most ancient tourism destination in the Balkans, so the topic of its tourism products should reflect the cultural and historic significance of this city. The excellent matter of cultural tourism products could imprison the characteristics of cultural attractions well.

Regenerate the product. The land of Chimera has involved additional means to make its products come alive. It uses the multi-media or Information Technology to show the process of establishing itself in a leading tourism destination in Albania. The innovative cultural tourism products can increase tourists' interests

${ }^{5}$ Roland Conrady, Martin Buck. Trends and Issues In Collaboration, p 212 
and make their travel entertained. Also, tourists can get a unique spiritual experience through the innovation of the cultural form.

Advance the participation. Himara encourages tourists to participate in the summer and coastline events or activities. They can participate in the endless games with the Ionian waves and navy blue, designing their own holidays and performing the local feasts with the residents. Those activities give tourists a chance to experience the local life style or living habit and also enhance the interaction between participants and the local people.

Face the cultural needs. Since most tourists who travel to Himara are mostly youngaged and well-educated, they may have a strong desire to know different cultures and tend to like attractions with rich history. Himara and its villages have established several travel schedules which could be linked most historic sites or heritage to the simple beach holidays. Additionally, most tourism destinations provide the travel brochures or books, which present the background and history of the attractions, to make tourists have a deep comprehension of the local culture. Tourism products should be formulated to know the market demands and satisfy those needs.

As previously mentioned, today, promotional activities through the internet and other electronic media including can be utilized. Central Government has taken necessary measures to encourage the private sector to play positive role in the development and diversification of tourist facilities to promote domestic and international tourism in the country. It has acknowledged a National Tourism Policy, recognizing tourism as an industry, a thrust sector in and taking appropriate measures to offer encouragement to both the local and foreign investors and tourists.

\section{References}

Roland Conrady, Martin Buck. Trends and Issues In Collaboration, Springer-Verlag Berlin Heidelbeg 2011

Scott McCabe, Marketing Communications in Tourism and Hospitality, Elsevier, Oxford, UK 2009

Ramos, Alejandro, D. Jimenez, Pablo, S. Tourism Development: Economics, Management and Strategy. Nova Science Publications, New York, 2008

Raju, G.P. Tourism Marketing and Management, Manglam Publications Dehli-II0053 (India), First Edition, 2009

Burns, Peter. M, Novelli, Marina.Tourism and Social Identities, Global Framework and Local Realities, Elsevier, Amsterdam 2006 
